\section{AS RESPOSTAS DA QUIMICA AO PROBLEMA DA ORIGEM DA VIDA}

É actualmente indubitável que a origem da vida não foi o resultado de uma "feliz coincidência»... mas uma etapa necessária na evolução da matéria. Trata-se de um aspecto inalienável do processo geral de desenvolvimento do Universo.

A.I.Oparin (1970)

Nem o Universo estava prenhe da vida, nem a biosfera estava prenhe do homem. A sorte saiu-nos no jogo em Monte Carlo. Não espanta pois que, tal como alguém que acaba de ganhar milhðes, sintamos a estranheza da nossa condição.

J.Monod (1970)

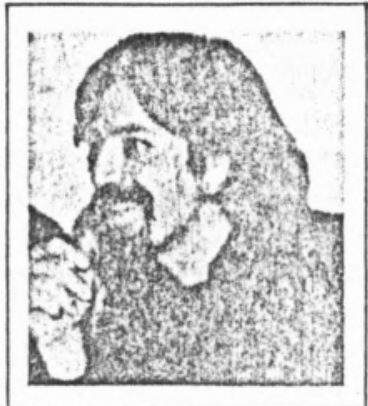

J.J. Moura Ramos

I.S.T

LISBOA

Nada é mais fascinante do que um mistério e não há mistério mais profundo que o mistério das origens. Mitologias e Folclore revelam a ancestral preocupação do homem pelo problema das origens: de si próprio, das espécies, da vida, da Terra, do Universo. As amplas especulações que se desenvolveram ao longo da História sobre este problema, dando lugar a lutas é controvérsias apaixonadas no campo da filosofia e da religiño, são a manifestação clara do fascinio cultural exercido sobre a humanidade pela problemática "original».

Ao longo da segunda metade do século XIX e do século $\mathrm{XX}$, com o desenvolvimento de ciências como it biologia, a astronomia, a física e a química, a discussão em torno destes problemas passou a assentar em bases

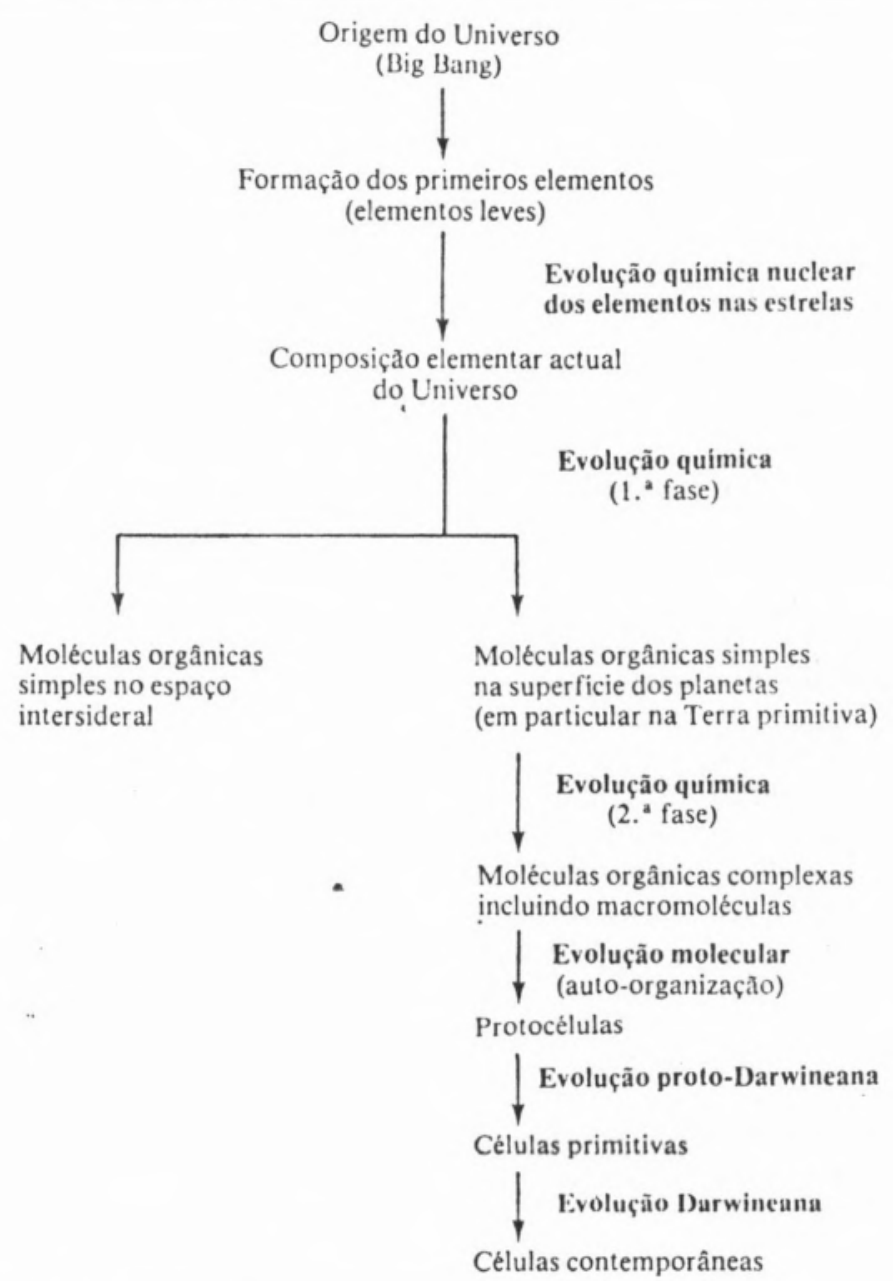


da vida. Surge aqui uma questão que me parece interes sante enunciar. Oparin, Haldane e Bernal, para além de cientistas dos mais prestigiados na sua época, eram militintes marxistas activos nos mais diversos campos da realidade social em que estavam inseridos. Qual a relação entre a posição político-ideológica destes homens, o periodo histórico em que viveram e a sua capacidade para alterar tão radicalmente o referencial da discussão sobre a origem da vida?

O estudo da origem da vida impõe, pela sua natureza intrinseca, uma abordagem interdisciplinar. Na última década assistimos a uma proliferação de revistas especializadas, congressos, publicações diversas que contam com a colaboração de cientistas de ramos tĩo diversos quanto a geologia e a geoquimica, a biologia e a bioquimica, a astronomia e a astrofisica, a quimica orgânica e a quimica-física... No estudo interdisciplinar da origem da vida a química ocupa uma posiçĩo primordial que só por si justifica a divulgação, no boletim da SPQ, dos aspectos essenciais da actual discussão cientilica sobre o assunto. Esta posição central da quimica no estudo da origem da vida ressalta claramente do diagra ma que a seguir se apresenta, em que se resumem as diferentes etapas da evoluçâo, desde a origem do Universo até à selecção darwineana das espécies. cientificas mais sólidas e a perder o seu carácter até entio predominantemente especulativo. No que respeita origem da vida, a grande rotura que possibilitou umi abordagem cientifica do problema, o corte epistemoló gico no dizer de alguns filósolos das ciências, loi a formulaçào, pelo bioquimico soviético A.I. Oparin (1924) pelo geneticista britânico J.B.S. Haldane (1928), da hi pótese segundo a qual a vida surgiu na Terra em condiços quimicamente redutoras, a partir de uma sequência evolutiva de acontecimentos nos quais teve lugar : sintese e a organizaçio de substâncias orgânicas du complexidade crescente que, na escala de tempo geológico, deram origem a sistemas vivos. Para Oparin Haldane não existe diferença fundamental entre um organismo vivo e a matéria inanimada: as combinaçỏes complexas, as manifestaçôes e as propriedades caracteristicas da vida são o resultado do processo de evoluçî́o da matéria. Estas ideias foram posteriormente desen. volvidas por J.D. Bernal, cristalógrafo, professor da Universidade de Londres, numa célebre comuniçaçio apresentada à British Physical Society em 1947 e intitu lada "As bases fisicas da vida".

As ideias de Oparin, Haldane e Bernal constituem a base em que assenta toda a investigação cientifica que actualmente se desenvolve sobre o problema da origem

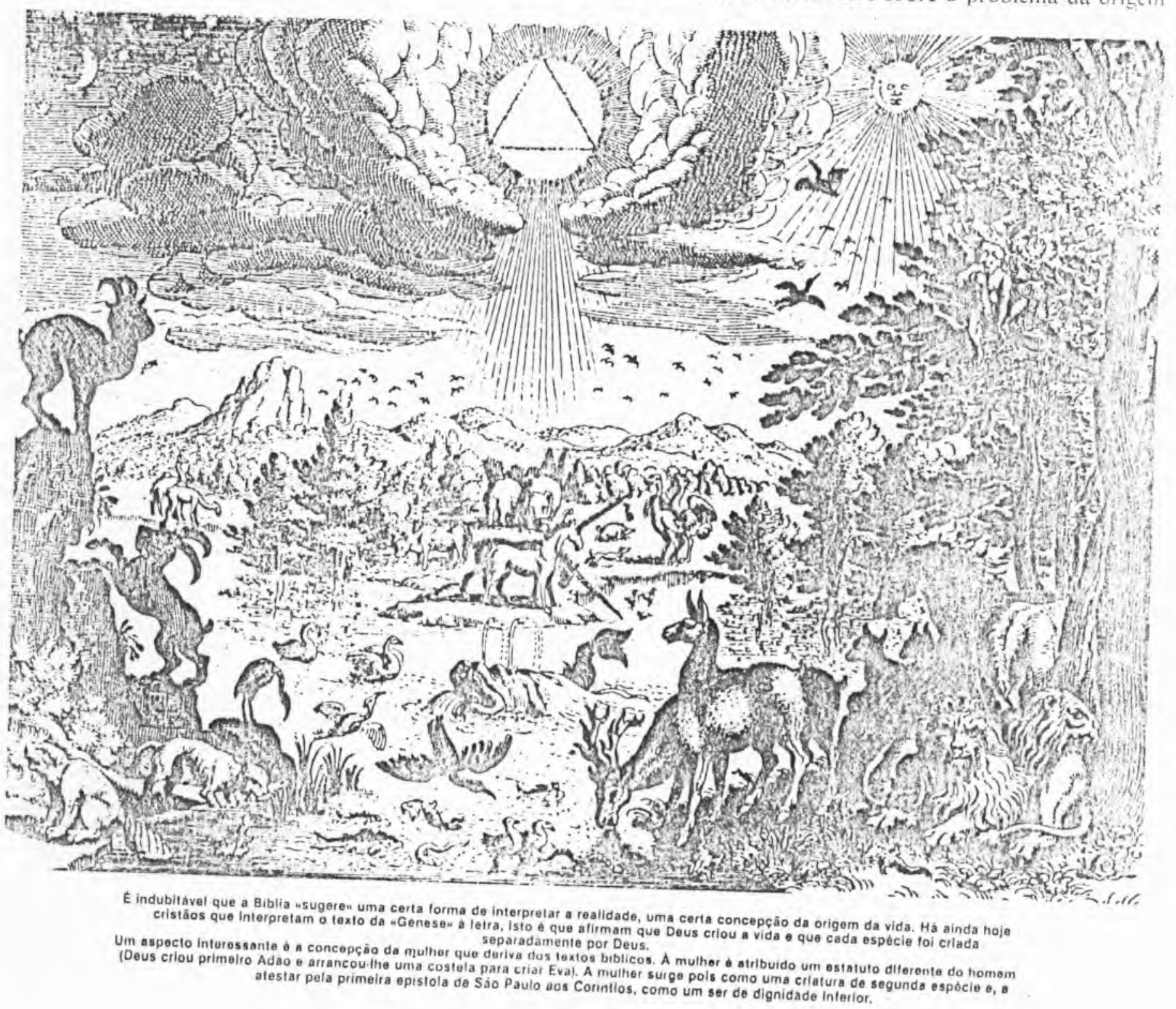




\section{A COSMOQUIMICA E A ORIGEM DA VIDA}

No contexto da problemática atrás referida, realizou-se recentemente (Junho de 1981), sob os auspicios da NATO, um curso subordinado ao tema: "Cosmoquímica e a Origem da Vida" $\left({ }^{*}\right)$. Neste curso, que se pretende seja o primeiro de uma série destinada a cobrir os múltiplos aspectos relevantes para o estudo interdisciplinar da origem da vida, o problema foi abordado numa perspectiva "analitica» $\left({ }^{* *}\right)$ isto é numa perspectiva de recolha de todas as informaçoes relevantes a partir da análise de diferentes tipos de material: análise das mais antigas rochas sedimentares existentes na crusta terrestre, antálise do solo e da atmosfera dos diferentes planetas do sistema solar, antálise da constituição de cometas e meteoritos, observação das moléculas existentes no espaço intersideral, etc... A recolha destas informaçðes, a par dos modelos teóricos existentes que permitem descrever a origem e evolução do Universo, a formação e evolução das galáxias e das estrelas, a formação do sistema solar, permite reconstituir um cenário que constitui o "background" a partir do qual se tornou possivel a evolução quimica e o aparecimento da vida na Terra.

No curso sobre "Cosmoquimica e a Origem da Vida» discutiram-se essencialmente as contribuições da astrofisica e da geoquimica para a reconstituição desse cenário; as linhas que se seguem constituem uma tentativa de sintetisar o quadro actual da discussão sobre este problema.

\section{1 - OS ELEMENTOS DA VII)A}

(V. VIOLA, Indiana University, USA)

Descreveu-se o processo que conduziu à formação dos elementos necessários à vida. Desde a sua origem há $10 \mathrm{Ga}\left({ }^{* * *}\right)$ (de acordo com a teoria do Big Bang), o Universo sofre um processo de expansão e consequente arrefecimento. Nas condiçōes iniciais, caracterizadas por temperaturas elevadissimas ( $10^{11}{ }^{\mathrm{a}} \mathrm{K}$ ), só existem particulas elementares: eram condiçð̄es demasiado drásticas para tornar possivel a existência de moléculas, átomos ou núcleos. Alguns minutos depois do "big-bang" (4 minutos) a temperatura já tinha descido a cerca de $10^{\prime \prime} \mathrm{K}$ o que possibilitou o inicio dos processos de nucleossintese de elementos leves (hidrogénio, deutério, litio). Mais tarde (700 000 anos), a temperatura era já de $3000 \mathrm{~K}$ e nesse periodo dá-se a formação de átomos.

No Universo em expansão, as flutuações de densidade dão lugar a regiōes de contraç̧āo yue estão na origem da formação das galáxias e das estrelas. Nestas regiōes o campo de gravitação aumenta localmente, e a densidade aumenta assim como a temperatura. As estrelas são sede de reacções que conduzem também à nucleossintese (e em particular à formação de núcleos pesados). Outra fonte menos importante de sintese de elementos no Universo provém da interacção entre raios cósmicos no espaço intersideral, que conduz à formação de núcleos leves tais como o litio, o berilio e o boro.

A formação dos elementos abre caminho a uma nova fase da evolução do Universo, normalmente designada por Evolução Quimica e que corresponde, na sua primeira fase, à formação das moléculas orgânicas mais simples, tanto no espaço intersideral como à superficie. dos planetas.

\section{2 - MOLÉCULAS ORGÂNICAS NO ESPAÇO (J.M. GREENBERG, University of Leiden, Holanda).}

A sintese molecular no espaço intersideral é descrita com base no chamado modelo dos grãos (grain model). O espaço intersideral é preenchido por uma poeira formada por grãos de pequenas dimensoes, constituidos por um núcleo contendo silicatos e/ou óxido de magnésio $(0,1$ milimicron cle diâmetro médio) e por uma crusta formada por elementos adsorvides (sobretudo $\mathrm{H}, \mathrm{N}, \mathrm{C}, \mathrm{O})$. A dimensão média destes grãos é de cerca de 0,25 milimicron. A colisão de fotōes UV $\left(10^{\circ}\right.$ $\mathrm{cm}^{-2} \mathrm{~s}^{-1}$ no espaço intersideral) com os grĩos dát lugar a fotoprocessos que conduzem at formaçaio de radlicatis e posteriormente de moléculas orgânicias (****).

Este processo de evolução química da crosta dos grãos no espaço intersideral foi objecto de experiências de simulação realizadas em laboratório. A comparação dos resultados obtidos nestas experiências de simulação com os dados existentes relativos à constituiçâo molecular do espaço intersideral constitui um razoável argumento em favor do "modelo dos grãos".

As moléculas orgânicas no espaço intersideral são detectadas essencialmente por radioastronomia e pelos métodos espectroscópicos clássicos. Os çonstituintes moleculares maioritários são, por ordem decrescente da sua abundância, o hidrogénio $\left(\mathrm{H}_{2}\right)$, o monóxido de carbono $(\mathrm{CO})$, a água $\left(\mathrm{H}_{2} \mathrm{O}\right)$ e a amónia $\left(\mathrm{NH}_{3}\right)$. Moléculas mais complexas e com importante papel no processo ulterior da Evolução Química, tais como $\mathrm{HCN}$, $\mathrm{NH}_{2} \mathrm{CHO}$, OCS, $\mathrm{HCCCN}, \mathrm{HCOOH}, \mathrm{CH}_{3} \mathrm{CHO}, \mathrm{H}_{2} \mathrm{CO}$, foram tambèm detectadas em quantidades significativas. Um problema que então se levanta é o de saber em que medida a matéria orgânica nas nuvens de poeira interestelar pode ter contribuido para o arranque e desenvolvimento do processo de Evolução Química na Terra. É geralmente aceite que, desde a sua formação há $4,6 \mathrm{Ga}$, o sistema solar já atravessou nuvens de poeira interestelar; para além da possibilidade de realização da sintese orgânica à superficie da Terra, este facto pode ter conduzido à acreção de matéria orgânica sobre a superficie do nosso planeta.

\section{3 - OS COMETAS E A ORIGEM DA VIDA}

(W.M. IRVINE, Chalmers University of Technology, Onsala Space Observatory, Sweden).

O interesse do estudo dos cometas neste contexto reside no facto de eles constituirem as mais primitivas amostras da nebula solar (a nuvem que, por condens:ção, deu origem ao sistema solar). Com efeito, ć hoje

(*) Este curso foi organizado por Cyril PONAMPERUMA, director do "Laboratory of Chemical Evolution" da Universidade de Maryland.

(**) A perspectiva "sintética" para o estudo da Evolıç̣̂o Quimica consiste em reproduzir no laboratório as condiçoes primitivas em! que a vida se desenvolveu com o objectivo de obter informatoes acerca dos mecanismos possiveis para essa evoluçio.

(**) $1 \mathrm{Ga}=1$ giga-ano $=10^{9}$ ano. Em alguns textos esta unidade de tempo é também designada por acon ( $\mathrm{AE}$ ).

(***) Não são apenas os fotoes UV que sato susceptivcis de musecat is sintese organica na pocira interestelar. () bombatcannento ds.

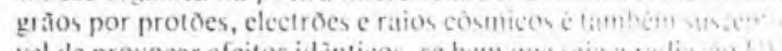

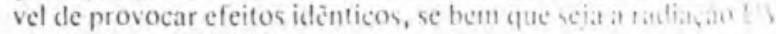
aquela que mais importincia assume neste processo. 
geralmente aceite que os cometas são constituidos essencialmente por um conglomerado pouco denso de gases solidificados (predominantemente água) contendo material idêntico áquele que se encontra nos meteoritos carbonáceos condríticos. A análise de composição dos cometas revela a existência de matéria orgânica (molèculas e radicais tais como $\mathrm{CH}, \mathrm{CN}, \mathrm{CO}, \mathrm{CS}, \mathrm{HCN}$, $\mathrm{CH}_{3} \mathrm{CN}$ ), inorgânica (moléculas e radicais como $\mathrm{H}, \mathrm{NH}$, $\mathrm{NH}_{2} \mathrm{OH}, \mathrm{H}_{2} \mathrm{O}$ Si, silicatos), metais ( $\mathrm{Na}, \mathrm{Ca}, \mathrm{Cr}, \mathrm{Co}, \mathrm{Mn}$, $\mathrm{Fe}, \mathrm{Ni}, \mathrm{Cu}, \mathrm{V})$ e iðes $\left(\mathrm{CO}^{+}, \mathrm{CO}_{2} ; \mathrm{CH}^{+}, \mathrm{CN}^{+} \mathrm{N}_{2} ; \mathrm{OH}^{+}\right.$, $\mathrm{H}_{2} \mathrm{O}^{+}$). Ao deslocarem-se na sua orbita em torno do Sol, os cometas perdem matéria, havendo evidência para a existência na atmosfera superior da Terra de particulas provenientes dos cometas.

Poderão os cometas ter um papel relevante na origem da vida? O principal problema na sintese de moléculas de interesse biológico na Terra é a polimerização de aminoácidos e de monómeros de ácidos nucleicos. Considera-se normalmente que estas reacçōes poderão ter ocorrido por desidratação devido ao aquecimento vulcânico e/ou evaporação e catálise em determinados contextos (lagunas, contacto proto-continentes oceano...). Condiçðes favoráveis para a realização destas reacções podem naturalmente ocorrer nos cometas em que o regime de temperaturas varia entre alguns graus acima do ponto de ebulição da água e alguns graus negativos, com superficies sólidas de metal e argila apropriadas para a catálise, e com possível circulação de soluçoes aquosas contendo material orgânico dissolvido em concentração superior às que existem nos oceanos terrestres. Os cometas poderão pois ter desempenhado um papel importante, transferindo para a Terra primitiva polimeros biológicos capazes de auto-replicação ou pelo menos capazes de evoluir no sentido dessa capacidade.

Outra fonte de transferência de matéria orgânica para a Terra são os meteoritos que caem à superficie numa quantidade estimada em $10^{4}$ toneladas por ano. A análise quimica desses meteoritos revela a presença de moléculas orgânicas já muito complexas tais como aminoácidos e bases de ácidos nucleicos de tipo porfirinico.

\section{4 - AMBIENTES PLANETÁRIOS E A ORIGEM}

DA VIDA (D. De VICENZI, Lile Science Division, NASA, USA)

Esta sessão do curso sobre "Cosmoquimica e a Origem da Vida» consistiu numa sintese das informaçōes recolhidas pelas missões espaciais da Nasa acerca das condições existentes na superficie e na atmosfera dos planetas do Sistema Solar. Na tabela seguinte dão-se alguns valores de parâmetros caracteristicos de alguns destes planetas:

\begin{tabular}{l|c|c|c|c}
\hline & $\begin{array}{c}\text { Diämetro relativo } \\
\text { a Terra }\end{array}$ & $\begin{array}{c}\text { Mawa relativa } \\
\text { á Terra }\end{array}$ & Densidade & $\begin{array}{c}\text { Distâtcia ao Sol } \\
\text { (relativa a Terfa) }\end{array}$ \\
\hline Mercúrio & 0,4 & 0,06 & 5,4 & 0,4 \\
Venus & 1 & 0,8 & 5,2 & 0,7 \\
Terrat & 1,0 & 1,0 & 5,5 & 1,0 \\
Marte & 0,5 & 0,1 & 4,0 & 1,5 \\
Jupiter & 11 & 31,8 & 1,3 & 5,0 \\
Saturno & 9 & 95 & 1,7 & 9,5 \\
\hline
\end{tabular}

A temperatura à superficie de Mercuirio é de $300 \mathrm{Ce}$ o bounbardeamento pela radiação UV proveniente do Sol é muito intenso. A densidade semellante à da Terra sugere que, devido à elevada temperatura, este planeta foi privado dos elementos mais leves.

No que diz respeito a Vénus, a temperatura à superfície é de $475^{\circ} \mathrm{C}$. Esta temperatura tão elevada (comparada com Mercúrio) explica-se pela composição da atmosfera deste planeta: $\mathrm{CO}_{2}(96 \%), \mathrm{N}_{2}(3,5 \%)$ e outros constituintes como $\mathrm{H}_{2} \mathrm{O}, \mathrm{O}_{2}, \mathrm{CO}$ e $\mathrm{SO}_{2}$ em concentrações atómicas da ordem do p.p.m. (parte por milhão), e pela sua pressão (cerca de $90 \mathrm{~atm}$ ). Estas condições dão lugar ao chamado efeito de estufa (greenhouse) que dit origem a uma amplificação do efeito térmico proveniente do Sol devido à reflexão pela atmosfera do calor irradiado pela superfície do planeta. Existe, para além disso, uma característica interessante do planeta Vénus que consiste no facto de existirem na sua atmosfera regioes em que ats condiçoes são semelhantes às da superficie da Terra $\left(\mathrm{p}=1 \mathrm{~atm} ; \mathrm{T}=27^{\circ} \mathrm{C}\right)$.

No que diz respeito a Marte, a pressão à superficic é de 8 milibar e a temperatura varia de $-143^{\circ} \mathrm{C}$ a $17^{\circ} \mathrm{C}$. $\wedge$ atmosfera deste planeta é constituida por $\mathrm{CO}_{2}(95 \%)$, $\mathrm{N}_{2}(2,7 \%), \quad \operatorname{Ar}(1,6 \%), \quad \mathrm{O}_{2}(0,1 \%), \quad \mathrm{CO}(0,07 \%)$, $\mathrm{H}_{2} \mathrm{O}(0,03 \%)$ e $\mathrm{O}_{3}(0,03$ p.p.m.). A análise do solo de Marte em diferentes locais (missão Viking, 1976) revela uma composição relativamente uniforme:

$$
\begin{array}{rl}
\mathrm{S}_{\mathrm{i}}-20,9 \% & \mathrm{Al}-3,0 \% \\
\mathrm{Fe}-12,7 \% & \mathrm{Cl}-0,7 \% \\
\mathrm{Mg}-5,0 \% & \mathrm{Ti}-0,5 \% \\
\mathrm{Ca}-4,0 \% & \text { Outros, } \\
\mathrm{S}-3,1 \% & \text { essencialmente }-50,1 \% \\
& \text { oxigénio }
\end{array}
$$

O solo de Marte é essencialmente constituido por argilas ricas em ferro e não foi detectada (à escala do p.p.m. - p.p.b.) matéria orgânica. O oxigénio cla atmosfera de Marte provém da fotodissociação da água e do anidrido carbónico e também de uma quimica particular, característica da superficie de Marte. Com efeito, as experiências realizadas com as amostras provenientes do solo de Marte revelam a presença de substâncias muito ricas em oxigénio (peróxidos). A existência destas rochas muito oxidantes e de uma radiação UV intensa explica a inexistência de moléculas orgânicas de interesse biológico sobre a superficie de Marte.

Em Júpiter a temperatura é de $-173^{\circ} \mathrm{C}$ a 0,1 atm e de $-113^{\circ} \mathrm{C}$ a 1 atm. Na atmosfera deste planeta existem moléculas como $\mathrm{H}_{2}, \mathrm{He}, \mathrm{CH}_{4}, \mathrm{C}_{2} \mathrm{H}_{2}, \mathrm{C}_{2} \mathrm{H}_{6}, \mathrm{NH}_{3}, \mathrm{PH}_{3}$, $\mathrm{H}_{2} \mathrm{O}$ e outras. A composição desta atmosfera é considerada como uma imagem da nuvem a partir da qual se condensou o sistema solar.

As informações existentes sugerem que é muito fraca a possibilidade de existência de formas de vida nos planetas do sistema solar. Em Marte há evidência para a existência, em épocas precedentes, de cursos de ágưa. Alguns autores sugerem, a partir da observação de mudanças de cor das rochas deste planeta, a existência de alguma actividade biológica. Esta hipótese não está no entanto confirmada.

\section{5 - A COMPOSIĊ̃̃O QUIMICA E A CLIMATOLOGIA NA ATMOSFERA} DA TERRA PRIMITIVA (A. HENDERSON-SELLERS, Nasa Institute for Space Studies, USA)

Contrariamente às ideias originais de Oparin e Haldane que consideravam que a vida na Terra teria resultado de um processo quimico prebiótico envolvendo 
i

os constituintes de uma atmosfyta fortemente redutora constituida essencialmente pelos gases $\mathrm{CH}_{4}, \mathrm{NH}_{1}$ e $\mathrm{H}_{2} \mathrm{O}$ libertados no processo de solidificação da crosta terrestre, os modelos recentes sugerem uma atmosfera neutra constituida por $\mathrm{CO}_{2}, \mathrm{H}_{2} \mathrm{O}$ e $\mathrm{N}_{2}$. A atmosfera terrestre constituiu-se quando da formação do planeta (4,6 Ga) como resultado da emissão de gases do seu interior. Durante os estádios mais primitivos da sua formação, e sob a aç̧ão das forças gravíticas, dá-se uma contraç̧ão da crosta. Este processo deu lugar a uma enorme libertação de calor. A actividade vulcânica era nesse perlodo muito intensa e os gases libertados eram essencialmente redutores $\left(\mathrm{NH}_{3}, \mathrm{CH}_{4}, \mathrm{H}_{2} \mathrm{O}\right)$. No entanto, sob o efeito da intensa radiação solar, estas moléculas foram rapidamente destruidas perdendo a atmostera as suas propriedades redutoras. Os modelos mais recentes sugerem que, 500 milhões de anos após a formação da Terra (data em que terá sido viável o aparecimento das primeiras formas primitivas de vida), a atmosfera já havia perdido as suas caracteristicas redutoras e era essencialmente constituida por $\mathrm{CO}_{2}, \mathrm{~N}_{2}$ e $\mathrm{H}_{2} \mathrm{O}$.

Esta alteração recente das concepçðes ácerca da constituição da atmosfera primitiva não modifica no entanto as ideias relativas à possibilidade de sintese prebiótica de moléculas de interesse biológico a partir dos constituintes atmosféricos e utilizando as fontes de energia então disponiveis (radiação UV, descargas eléctricas, etc...). Com efeito, experiências recentes de simulação realizadas em laboratório mostram a possibilidade de obter moléculas de interesse biológico a partir de misturas gasosas contendo $\mathrm{CO}_{2}, \mathrm{~N}_{2}$ e $\mathrm{H}_{2} \mathrm{O}$ submetidas a descargas eléctricas. A presença de $\mathrm{NH}_{3}$ facilitava no entanto a realização de tais reacçoes pelo que alguns investigadores admitem a hipótese de existência de reacções químicas à superficie da Terra que constituiram fontes de amónia (por exemplo a irradiação UV de azoto adsorvido numa superficie de óxido de titânio $\left(\mathrm{TiO}_{2}\right)$ conduz à formação de $\mathrm{NH}_{7}$ ).

Do ponto de vista climatológico a atmosfera terrestre caracteriza-se por uma grande estabilidade que resulta da formação muito antiga do oceano com a consequente criação do ciclo hidrosférico ${ }^{(.)}$.

A temperatura à superfície da Terra sofreu, de acordo com os mais recentes modelos, alterações ao longo da sua história. Numa fase inicial (até cerca de 3,5-3,8 Ga) terá havido um aumento de temperatura devido ao efeito da intensa radiação solar (efeito de estufa) e da radioactividade acumulada no interior da Terra durante o período inicial da sua formaçâo. A este periodo segue-se um outro $\mathrm{em}$ que a temperatura decresce devido ao anulamento do efeito de estula (associado com a modificação da composição atmosférica) e à condensação da água nos oceanos. Actualmente a temperatura da superficie da Terra apresenta-se estável, com uma pequena variação ao longo do tenıpo que está relacionada com a variação da luminosidade solar.

\section{6 - A DATAÇÃO DOS MAIS ANTIGOS SEDIMENTOS DA TERRA (S. MOORBATH, University of Oxford)}

A datação das rochas faz-se a partir da sua análise isotópica e baseia-se na construção dos chamados diagramas isócronos (ver bibliografia). As mais antigas rochas sedimentares actualmente conhecidas à superfï- cie da Terra situam-se na Gronelândia (maciço de lsua) e formaram-se há $3,8 \mathrm{Ga}$. Trata-se de uma formaçĩo constituida por camadas alternadas de magnetite e de carbonatos, formação esta que se designa genericamente por "banded iron formation" (B.I.F.). O processso de sedimentação ocorreu no fundo dos oceanos. Nesse tempo $(3.8 \mathrm{Ga})$, não havia praticamente continentes; a superficie da Terra era um imenso oceano, de quando em quando ornamentado por pequenas ilhas vulcânicas que constituiam como que pré-continentes. Por outro lado a atmosfera não continha $\mathrm{O}_{2}$ e, nessas condiçoes, o ferro existia sob a forma reduzida $\left(\mathrm{Fe}^{2+}\right)$, solúvel. A precipitação da magnetite implica a existência de uma fonte de oxigénio para oxidar o ferro a $\mathrm{Fe}^{3+}$ que, sendo insoluvel, precipita. Alguns autores atribuen a estas rochas um carácter biogénico por considerarem que a fonte de oxigénio seria biológica (organismos primitivos).

As rochas de ISUA foram fortemente metamorfoseadas por aquecimento e deformação intensos em períodos posteriores à sua formação, pelo que a análise directa da vida nestas rochas se torna muito dificil. Aliảs, a análise das formas mais elementares de vida na Terra primitiva é uma tarefa geralmente dificil: se a evidência para a existência de vida é clara, as rochas sedimentares não são na generalidade muito antigas; se as rochas são muito antigas, a evidência para a existência de vida é geralmente pouco convincente. Recentemente descobriram-se em Pilbara (Austrália ocidenta!) e no Zimbawe, estromatolites (formações sedimentares formadas por algas e possivelmente outros organismos) com 3,4 e 3,5 Ga. Trata-se dos mais antigos macrofósseis até hoje descobertos. Recorde-se por outro lado que é possivel que os sedimentos de lsua $(3,8 \mathrm{Ga})$ tenham um carácter biogénico. Estes factos, conjuntamente com os resultados de outros estudos recentes, sugerem que a vida apareceu muito cedo na história da Terra. E difici! aceitar que a superficie do nosso planeta fosse hospitaleira para as formas mais elementares de vida antes de 4,2 ou $4,3 \mathrm{Ga}$ (bombardeamento intenso da Terra por objectos ainda resultantes da condensação da nébula solar, bombardeamentos esses que causavam fortes turbulências provavelmente hostis ì sobrevivência das formas primitivas de vida). Portanto, se a vida se desenvolveu na Terra, o processo que a ela conduziu deverá ter ocorrido muito rapidamente. Algumas centenas de milhões de anos, não são nada na escala geológica de tempo.

\section{7 - ASPECTOS DA QUIMICA BIO-INORGÂNICA RELACIONADOS COM A ORIGEM F \\ EVOLUÇÃO DA VIDA (E. OCHIAI, Laboratory of Chemical Evolution, University of \\ Maryland, USA)}

O papel das espécies inorgânicas no processo que conduziu à formação da vida pode ser descrito considerando quatro etapas distintas:

ETAPA 1: Sintese abiótica dos compostos essenciais (amino-ácidos, carbohidratos, lipidos, porfi-

(.) Para o estabelecimento desta estabilidade climática muito terá contribuido a Lua que, pela sua massa, conduziu a uma fixaçito da posiçăo do eixo terrestre com o consequente estabelecimento de sucessão regular das estaçoes e das marés. 
rinas, etc...). As experiências de simulação sugerem que estes compostos essenciais podem ter sido formados por via abiogénica. Nas reacçðes subsequentes (em meio aquoso) as espécies inorgânicas (iðes metálicos, etc...) podem coordenar os intermediários ou os produtos dos processos de evolução química ou catalisá-los. Inúmeros exemplos se podem dar do papel de espécies inorgânicas nestes processos.

ETAPA 2: Formação abiótica de compostos polimétricos tais como péptidos (proteinas), ácidos nuclei$\cos$ e polissacaridos. Estas reacçôes de condensação, geralmente endotérminas, foram objecto de experiências de simulação utilizando agentes desidratantes (polifosfato ou diaminomaleonitrilo) ou aquecendo até à secura uma solução de aminoácidos. O papel dos compostos inorgânicos parece ser importante na imposição de um carácter selectivo para a reacção de polimerização. Por exemplo, na molécula de ferredoxina, a geometria cúbica do $\mathrm{Fe}_{4} \mathrm{~S}_{4}$ parece ser determinante na criação das restriçðes estereoquimicas caracteristicas da sua estrutura molecular.

ETAPA 3: Formação do sistema: protobionte. Formação de membranas, coacervatos, etc...

ETAPA 4: Formação de sistema em interacção adequada: vida... código genético, sistematização das reacçðes quimicas, selectividade das enzimas, etc... O DNA e o RNA in situ contêm iðes metálicos tais como o $\mathrm{Mg}(\mathrm{II}), \mathrm{Ni}(\mathrm{II}), \mathrm{Cr}$ (III) que estão situados em posiçðes estratégicas de forma a manter a conformação especifica dos ácidos nucleicos. $\mathrm{O} \mathrm{Ca}(\mathrm{II})$ desempenha papel importante na estruturação da membrana celular (papel na formação de coacervatos e protocélulas?).

Os aspectos bioinorgânicos da Evolução Biológica primitiva estâo relacionados com os potenciais de redução dos elementos e consequentemente com a concentração de oxigénio na atmosfera. As etapas mais importantes são: 1) Num primeiro periodo $(4,5-3,5 \mathrm{Ga})$ os elementos existem em estados reduzidos (quantidade de $\mathrm{O}$, muito reduzida). 2) Num segundo periodo (3,5$-2,1 \mathrm{Ga}$ ) desenvolvem-se as formas mais primitivas de vida. Deixa de existir amónia na atmosfera e há um ligeiro aumento da quantidade de oxigénio. O molibdénio passa a ser abundante nos oceanos sob a forma de $\mathrm{MoO}_{4}^{2}$ (solúvel). O carbono transforma-se cada vez mais em $\mathrm{CO}_{2}$. 3) Num terceiro periodo $(2,1-1,4 \mathrm{Ga})$ surgem as algas azuis-verdes. $\mathrm{O}$ enxofre existe essencialmente na forma sulfato. Forte aumento de $\mathrm{O}_{2}$ na atmosfera. $\mathrm{O}$ cobre passa a existir na forma $\mathrm{Cu}(\mathrm{II})$. 4) Num quarto periodo $(1,4-0,5 \mathrm{Ga})$ surgem as células eucariotas e relorçil-se o metabolismo aeróbico. Passa a existir azoto sob a forma de nitrato cujo potencial de redução é idênlic() alo do oxigénio.

\section{8 - FRACCIONAMENTO ISOTÓPICO NOS SEIIIMENTOS MAIS ANTIGOS}

I)A TERRA (M. SCHIDLOWSKI, Precambrian Research Group, Los Angeles, USA)

$\mathrm{O}$ estudo da composição isotópica do carbono (e lambèm do enxofre) nas rochas sedimentares mais antigas pode fornecer indicaçoes sobre o carácter biogénico destas rochas. O carbono, elemento essencial para a vida, aparece sob duas formas: 1) carbono oxidado
$\left(\mathrm{CO}_{2}\right.$ na atmosfera, carbonatos e bicarbonatos nos oceanos); 2) carbono orgânico reduzido (carbohidratos, proteinas, lipidos...). A formação das rochas sedimentares realiza-se nos oceanos (baixas temperaturas). Nestas condiçđes a redução do carbono é um processo essencialmente biológico (fixação do carbono). Nos processos metamórficos pođem ocorrer reacçðes de redução que não têm carácter biológico.

O processo de redução do carbono (assimilação do $\mathrm{CO}_{2}$ pelos organismos) podem ser descritos da seguinte forma:

$$
\begin{aligned}
& \mathrm{CO}_{2} \text { (exterior) } \rightleftharpoons \mathrm{CO}_{2} \text { (interior) } \rightarrow \mathrm{RCOOH} \\
& \text { DIFUSĀO "CARBOXILAÇÃO }
\end{aligned}
$$

No processo de difusão do $\mathrm{CO}_{2}$ para o interior dos organismos a alteração da composição isotópica do carbono é muito reduzida. Pelo contrário, no processo de carboxilação, existe um significativo frāccionamento isotópico resultante de um efeito cinético imposto pela fotossintese e pela respiração anaeróbica e que leva a uma acumulação de isótopos leves $\left({ }^{12} \mathrm{C}\right)$ nos organismos. Este fraccionamento isotópico é preservado nas rochas sedimentares.

A análise isotópica dos carbonatos das rochas sedimentares de diferentes idades revela uma constância ao longo do tempo. Esta mesma constância é observada para a composição isotópica do carbono orgânico e isto até épocas tão recuadas como $3,8 \mathrm{Ga}$ (rochas de Isua, Gronelândia). Esta constância da composição isotópica do carbono orgânico sugere que o ciclo do carbono já estava estabilizado na Terra há $3,8 \mathrm{Ga}$ ou seja que, nesta época, já existiam provavelmente processos bioquimicos associados à existência de organismos elementares.

\section{9 - AS MOLÉCULAS ORGÂNICAS COMO FÓSSEIS MOLECULARES EGLINTON, Organic Geochemistry Unit, University of Bristol)}

Em sentido lato, a palavra "fossil» refere-se a qualquer evidência de vida primitiva. É usual introduzir uma distinção formal entre os chamados fosseis morfológicos (evidência morfológica de organismos existentes em épocas recuadas - os fósseis dos paleontologistas) e os chamados fósseis moleculares (compostos orgânicos constituintes desses organismos).

Determinados tipos de compostos orgânicos (alcanos, ácidos gordos de elevado peso molecular, pigmentos porfirínicos) surgem como promissores marcadores biológicos dada a sua estabilidade durante longos períodos de tempo e quando submetidos às condiçōes dos processos geológicos. Os alcanos lineares são moléculas orgânicas frequentemente encontradas como constituintes dos organismos actuais. Os compostos contendo um número impar de átomos de carbono parecem ser mais abundantes nos organismos vivos do que os que contêm um número par. Esta observação tem sido utilizada por alguns autores para fundamentar o carácter biogénico de rochas sedimentares.

Os compostos de tipo isoprenóide são particularmente úteis como marcadores biológicos dado o seu elevado grau de especifidade estrutural aliado à stat ampla ocorrência na natureza. Por exemplo, o pristano $(2,6,10,14$-tetrametilpentadecano) e outros hidrocar- 
bonetos isoprenóides foram isolados do petróleo bruto de idades intermédias (Mesozóico, Paleozóico) em concentraçðes apreciáveis, assim como de rochas sedimentares mais antigas (Precambriano). O pristano é um conhecido constituinte dos seres vivos (zooplacton, óleos de peixe e de cetáceos, esponjas marinhas...) mas a fonte do material mineralizado pode ser a porção fitol da clorofila degradada quer por processos biogénicos quer por processos abiogénicos.

O fitano $(2,6,10,14$-tetrametil hexadecano) foi também detectado em rochas com mais de $1 \mathrm{Ga}$. A presença de pristano e de fitano nas rochas é considerada como indicativa da existência, na época da sua formação, de processos fotossintéticos.

A extracção de material orgânico das rochas sedimentares exige técnicas por vezes muito delicadas. Por outro lado, o problema de saber se o material orgânico extraido é indigeno ou se, pelo contrário, é fruto de uma contaminação posterior à formação das rochas, é um problema central da investigação neste campo. Apesar destas dificuldades, a geoquimica orgânica tem nestes últimos anos contribuido decisivamente para o estudo do problema da origem da vida.

\section{BIBLIOGRAFIA SUMȦRIA}

1) Textos de carácter geral sobre o problema da origem da vida:C. PONAMPERUMA, "The origins of lile", Thames and Hudson, London (1972)

D. GOLDSMITH T. OWEN, "The Search for life in Universe» Benjamin/Cummings Publishing Co. (1980)

2) Sobre a origem do universo e a nucleossintese: S. WVEINREB," Les trois premiéres minutes de l'univers," Editions du Seuil, (1979)

V.TRIMBLE, The origin and abundances of the chemical elements, Rev. Mod. Plıys. 47, 877 (1975)

3) Sobre as reaç̧oes quimicas no espaço intersideral ec o papel dos cometas na origem da vida

J.M. GREENBERG, Chemical Evolution of Interstellar Dust - a source of prebiotic material?, a publicar
W.H. IRVINE, S.B. LESCHINE, F.P. SCHLOERB, Thermal History, Chemical Composition and Relationship of Comets to the Origin of Life, Nature, 283, 748 (1980)

W.M. IRVINE, S.B. LESCHINE, F.P. SCHLOERB Comets and the Origin of Life, in "Origin of Life", Y. Wolman editor, D. Reidel Publishing Co. (1981)

4) Sobre a composição da atmosfera primitiva

J.C.G. WALKER, "Evolution of the atmosphere", MacMillan, New York (1977)

A. HENDERSON-SELLERS, A.W. SCHWART7., Chemical Evolution and ammonia in the early Eartli's atmosphere, Nature, 287, 526 (1980)

5) Os sedimentos mais antigos da crosta terrestre e as informaçðes sobre a origem da vida

S. MOORBATH, The oldest rocks and the growth of continents, Scientific American, Março de 1977 , pgs. 92-104

M.T. McCUllOCH, G.J. WASSERBURG, Sm-Nd and $\mathrm{Rb}-\mathrm{Sr}$ chronology of continental crust formation, Science, 200, 1003 (1978)

E.G. NISBET, Archaean stromatolites and the search for the earliest life, Nature 284, 395 (1980)

6) Sobre os aspectos bioinorgânicos da origem e evolução da vida

M.T. BECK, in "Metal Ions in Biological Systems", vol, 7, Marcel Dekker (1978)

E.I. OCHIAI, The evolutions of the environment and its influence on the evolution of life, Origins of Life 9 , 81 (1978)

7) As moléculas orgânicas como fósseis moleculares K.A. KVENVOLDEN editor, "Geochemistry and the origin of lifes, cap. IV, Dowden, Hutchinson and Ross, Inc. (1974)

S.C. BRASSEL, G. EGLINTON, Biochemical significance of a novel sedimentary $C_{27}$ stanol, Nature 290, 579 (1981).

S.C. BRASSEL, A.M.K. WARDROPER, I.D. THOMSON, J.R. MAXWELL, G. EGLITON, Specific acyclic isoprenoids as biological markers of methanogenic bacteria in marine sediments, Nature, 290, 693 (1981)

\section{INVOTAN}

\section{LISTA DOS BOLSEIROS NO ESTRANGEIRO TRABALHANDO EM QUIMICA E AREAS AFINS}

- Maria Madalena Ramos de Lemos Araújo Humanes Licenciada em Quimica

Departamento de Quimica do "London University College".

- Elisa Maria da Silva Campos

Licenciada em Quimica

Laboratório de Fisiopatologia dos Lipidos da Faculdade de Farmácia da Universidade de Lille.

- Maria da Graça Bontempo Vaz Rasteiro Vinhas Licenciada em Engenharia Quimica

Departamento de Engenharia Quimica da Universidade de Birmingham.

- Jaime Isidoro Naylor da Rocha Gomes Licenciado em Quimica Têxtil
Department of Colour Chemistry and Dyeing - Universidade de Leeds.

- Maria João Ribeiro Nunes Ramos

Licenciada em Quimica

Departamento de Quimica da Universidade de Glasgow.

- Maria Helena Mendes Gil Licenciada em Fisico-Quimica

Department of Colour Chemistry and Dyeing - Universidade de Leeds.

- Maria Helena Figueira Vaz Fernandes Licenciada em Engenharia Quimica

Departamento de Cerâmicas da Universidade de Sheffield.

- José Carlos Brito Lopes

Licenciado em Engenharia Quimica

Departamento de Engenharia Quimica da Universidade de Houston. 